This is the author's final, peer-reviewed manuscript as accepted for publication. The publisher-formatted version may be available through the publisher's web site or your institution's library.

\title{
Understanding the decision to marry versus cohabit: the role of interpersonal dedication and constraints and the impact on life satisfaction
}

Matthew D. Johnson, Jared R. Anderson, C. J. Aducci

How to cite this manuscript

If you make reference to this version of the manuscript, use the following information:

Johnson, M. D., Anderson, J. R., \& Aducci, C. J. (2011). Understanding the decision to marry versus cohabit: The role of interpersonal dedication and constraints and the impact on life satisfaction. Retrieved from http://krex.ksu.edu

\section{Published Version Information}

Citation: Johnson, M. D., Anderson, J. R., \& Aducci, C. J. (2011). Understanding the decision to marry versus cohabit: The role of interpersonal dedication and constraints and the impact on life satisfaction. Marriage \& Family Review, 47(2), 73-89.

Copyright: Copyright $\odot$ Taylor \& Francis Group, LLC

Digital Object Identifier (DOI): doi:10.1080/01494929.2011.564525

Publisher's Link: http://dx.doi.org/10.1080/01494929.2011.564525

This item was retrieved from the K-State Research Exchange (K-REx), the institutional repository of Kansas State University. K-REx is available at http://krex.ksu.edu 
Running head: DECISION TO MARRY

Understanding the Decision to Marry Versus Cohabit: The Role of Interpersonal Dedication and Constraints and the Impact on Life Satisfaction

Matthew D. Johnson

Jared R. Anderson

C. J. Aducci

Kansas State University

Correspondence concerning this article should be addressed to Matthew D. Johnson, Kansas State University, School of Family Studies and Human Services, 204 Campus Creek Complex, Manhattan, KS 66506. Telephone: 785-532-6984. Fax: 785-532-6523. E-mail:

mjohns18@ksu.edu 


\begin{abstract}
The current study explored men and women's reasons for choosing to marry rather than to cohabit using a national dataset $(n=786)$ of adults who were currently married or had been married previously. Utilizing commitment theory, participant's open-ended reasons for choosing to marry were coded into categories of either interpersonal dedication or constraint commitment. A variety of demographic, attitudinal, and relationship history variables were then used to predict commitment type. The influence of commitment type during the decision to marry on life satisfaction was also explored. Results indicate that current marital status (being married versus being divorced or separated) and cohabiting prior to marriage were the strongest predictors of interpersonal dedication reasons for marriage for both men and women. Level of conventionality and parents' marital status also emerged as significant predictors of constraint commitment. Finally, marrying for reasons related to interpersonal dedication significantly predicted higher life satisfaction for men but not for women.
\end{abstract}


Dramatic increases in cohabitation, coupled with an increasing age at first marriage and a decline in the marriage rate, have changed the family formation landscape in the United States. The majority of first marriages in the United States are now preceded by cohabitation with one or more partners (Bumpass \& Lu, 2000) and, as a result, cohabitation has been labeled a "dominant family form" in the U.S. culture (Manning \& Bulanda, 2006, p. 199). In addition, over half of adolescents intend to live with at least one partner prior to marrying (Manning, Longmore, \& Giordano, 2007), most likely because about $60 \%$ of young adults believe living together prior to marriage will help with later marital happiness and stability (Wilcox \& Marquardt, 2009).

Despite these dramatic increases in cohabitation rates and the increasing age at first marriage, the vast majority of young adults in the U.S. continue to aspire to marry and will do so at some point in their lifetime (Thornton \& Young-DeMarco, 2001). In light of these societal trends, couples are increasingly faced with the decision to cohabit or marry. The purpose of the current study is to examine the commitment-based reasons individuals provide in choosing to marry rather than cohabit and how various demographic, attitudinal, and personal well-being variables are related to these commitment-based reasons for choosing marriage. Interpersonal commitment, which has been found to be an important construct in understanding romantic relationships and personal well-being (Givertz \& Segrin, 2005; Rhoades, Stanley, \& Markman, 2009a), could be an important variable in understanding why individuals choose marriage and how those choices influence personal well-being.

\section{Interpersonal Commitment}

Several models of interpersonal commitment can be found in the literature (Adams \& Jones, 1997; Arriaga \& Agnew, 2001; Johnson, Caughlin, \& Huston, 1999; Stanley \& Markman, 1992). In this paper, we focus on Stanley and Markman's (1992) more parsimonious model, 
which has been widely used in recent research investigating the transition from cohabitation to marriage (Kline et al., 2004; Rhoades, Stanley, \& Markman, 2009b; Stanley, Rhoades, \& Markman, 2006) and has proven to be a salient factor in distinguishing those cohabiters who are most at risk for later marital distress.

Stanley and Markman (1992) proposed that there are two essential components of interpersonal commitment, forces that motivate connection (personal dedication) and forces that increase the costs of leaving (constraints). Personal dedication encompasses all of the positive factors associated with the partner and relationship. The dimensions that comprise personal dedication are the desire for the relationship to endure into the future, placing a high priority on one's relationship, strong sense of couple identity, finding satisfaction in sacrificing for the partner, and lack of interest in alternative partners. Constraints are the barriers that make ending a relationship more difficult, regardless of one's personal dedication. The dimensions of constraint, according to Stanley and Markman, are accumulation of joint possessions and financial investment, social or religious pressure, difficulty associated with terminating the relationship, unattractive alternatives, and a lack of other suitable partners. Put another way, personal dedication refers to those reasons keeping an individual committed to a relationship because he or she wants to be in that relationship; whereas, constraints are all of the factors keeping the individual in a relationship because he or she has to or ought to be in that relationship.

Gender has proven to be a critical component in understanding commitment levels and types. Previous research has consistently demonstrated that men report lower overall levels of global commitment than women in personal relationships (Murstein \& MacDonald, 1983; Sabatelli \& Cecil-Pigo, 1985). Related to dedication and constraint commitment, men tend to 
have more significant increases in levels of both dedication and constraint commitment as relationships progress from dating to marriage, whereas for women, their levels of each type of commitment stay more consistent as they move through the relationship continuum (Givertz \& Segrin, 2005).

\section{Factors Associated with Dedication and Constraint Commitment}

The influence of basic demographic variables, including age, level of education, and income, on type of commitment (dedication and constraint) has not been explored in the literature. This is most likely due to the fact that the extant knowledge base has been developed through the use of convenience samples that are fairly homogenous in relation to demographics (Adams \& Jones, 1997; Givertz \& Segrin, 2005), with few exceptions (Stanley, Whitton, \& Markman, 2004). Since the current study uses a national sample, basic demographic variables are included in the analyses to control for their influence.

The relationship between conventional societal beliefs and commitment type has been investigated only in conjunction with other relational variables (Givertz, Segrin, \& Hanzal, 2009). Couples with a more conventional belief system (compared to those with more progressive beliefs), who are more relationally interdependent psychologically and behaviorally (as opposed to more autonomous in these domains), and who engage in conflict primarily around serious issues (as opposed to avoiding conflict or engaging in conflict around trivial issues) hold the highest levels of dedication commitment and lowest levels of constraint, which "appears to be yoked to a traditional value system and driven by ideology rather than rewards" (Givertz et al., 2009, p. 578). In other words, traditional values may orient couples to interact in ways that may result in higher levels of dedication. The current study examines the relationship between specific conventionality variables (beliefs about divorce and premarital sex) separate from 
relationship process variables to more specifically assess the relationship between conventionality and the type of commitment endorsed in deciding to marry rather than cohabit.

Parental divorce has been found to be associated with one's commitment. For example, men from divorced families, compared with those from intact families, endorse higher levels of constraint commitment in their interpersonal relationships (Jacquet \& Surra, 2001), yet experiencing parental divorce does not seem to be related to dedication commitment (Whitton, Rhoades, Stanley, \& Markman, 2008). The opposite seems to be the case for women. Parental divorce was not associated with constraint commitment for women (Jacquet \& Surra, 2001), but experiencing a parental divorce was associated with significantly lower levels of dedication commitment (Whitton et al., 2008).

The current investigation also explores how cohabitation history and current marital status are related to commitment type (i.e., personal dedication or constraint commitment) in the decision to marry. Dedication and constraint commitment are known to be salient factors in explaining later marital functioning in cohabiting relationships (Rhoades et al., 2009b; Stanley et al., 2006). More specifically, the decision to marry prior to cohabiting together mitigates the risk of later marital problems commonly associated with cohabitation. However, couples that choose to marry after a period of cohabiting are often pulled into marriage due to the increased constraints cohabitation naturally brings and are, ultimately, more at risk for later marital distress. Therefore, examining the role of prior cohabitation in relation to dedication and constraint reasons for marriage would represent a contribution to this literature. On the other hand, whether current marital status is related to commitment type in one's reason for marriage has yet to be investigated and is exploratory at this time. It could be hypothesized that individuals marrying primarily for reasons of constraint might be at greater risk for later marital 
dissolution. The current study explores that possibility retrospectively, asking currently married and divorced individuals what their motivation for marrying rather than cohabiting was at the time of their marriage.

\section{Commitment and Personal Well-Being}

There is preliminary evidence that the type of commitment that currently defines a relationship is linked with personal well-being. In a sample of cohabiting couples, Rhoades, Stanley, and Markman (2009a) found that individuals in relationships characterized by higher levels of constraint had lower levels of personal well-being (i.e., higher levels of depression and anxiety), lower levels of relationship quality, and their relationships evidenced higher levels of aggressive behavior. However, to our knowledge researchers have yet to investigate whether the type of commitment (dedication versus constraint) that defines a person's reason for marriage is related to life satisfaction, a common personal well-being variable. Specifically, is an individual's primary commitment motivation (personal dedication vs. constraint) for marrying their partner (rather than cohabiting with their partner) associated with their life satisfaction? Given the strong association between type of commitment and relationship quality (Stanley et al., 2004) and type of commitment and personal well-being (Rhoades et al., 2009a), this is a potentially important area of exploration.

The current study seeks to answer the following research questions:

1. What demographic, attitudinal, and relationship history variables are most predictive of personal dedication or constraint commitment in the decision to marry (rather than cohabit)?

2. Is an individual's reason for marriage (personal dedication vs. constraint) associated with that individual's level of life satisfaction when controlling for demographic variables? 


\section{Method}

The current study uses data obtained as part of the marriage and parenthood study from the Social and Demographic Trends department of the Pew Research Center (2007). The study was conducted in 2007 by Princeton Survey Research International. Data were gathered through telephone interviews with a nationally representative sample of 2,020 adults living in households with a telephone. Random-digit dialing methodology was employed to ensure the generalizability of the sample and the interviews were conducted in both Spanish and English. The response rate was $23.2 \%$ (working rate $=48.5 \%$, contact rate $=67.5 \%$, cooperation rate $=$ $36.6 \%$, eligibility rate $=66.1 \%$, completion rate $=93.8 \%$, which is consistent with other studies employing a similar methodology (for a review, see Holbrook, Krosnick, \& Pfent, 2008). The questionnaire was developed by Pew Research Center staff and was piloted prior to administration. To allow for separate analyses of African American, Hispanic, and 18 to 49 year old respondents, these groups were oversampled. Therefore, a weighting variable was used in all analyses to control for the oversampling technique.

Because our primary question of interest asked participants why they chose to marry as opposed to cohabit, we limited our sample to those individuals for whom cohabitation would have been a reasonably viable social option. In a review of the cohabitation literature, Smock (2000) noted that only a very small percentage of people cohabited before marriage prior to the 1970s. Following methods used in other research examining cohabitation in a nationally representative sample (Bumpass \& Lu, 2000), only the 18 to 49 year olds were used in the current study, reducing the total number of participants to 1,189 . Of the 18 to 49 year-olds, just over two thirds of the sample were currently or had been married in the past. Those who had never married were excluded from the analyses, reducing the number of eligible participants to 
786. Finally, missing data was handled using listwise deletion, which resulted in a further reduction of participants for each model.

\section{Sample}

The sample was comprised of $51.7 \%$ females and $48.3 \%$ males. The mean age of respondents was 36.4 years. Nearly $70 \%$ of those in the sample were White, $9.8 \%$ identified as Black, $12.7 \%$ were Hispanic, and just over 5\% belong to another racial group. About one quarter of the sample reported a total household income under $\$ 30,000,46.9 \%$ made between $\$ 30,000$ and $\$ 74,999$, with the remaining 30.9\% making over $\$ 75,000$ a year. Just over two-fifths of the sample graduated from high school or received a GED (40.2\%), 23.3\% had some college education, and $32.3 \%$ held a college degree.

Seventy-four percent of the sample was currently married when the data were collected, $10.0 \%$ were divorced, $1.7 \%$ were widowed, $9.0 \%$ were living with a partner, and $5.2 \%$ were currently separated. Of those not currently cohabiting, over $40 \%$ had previously lived with a partner without being married. Out of all those that had cohabited, $64.6 \%$ lived with their current spouse, $7.9 \%$ lived with someone else, and $25.8 \%$ lived with their current spouse and had previously lived with someone else.

\section{Variables}

Table 1 contains correlations of all study variables for men and women.

Control variables. Three demographic variables were used as controls for the logistic regressions: age, highest level of education completed, and total family income. Age was entered as a continuous variable ranging from 18 to 49 . Total family income was left as a categorical variable ranging from under $\$ 10,000$ a year (1) to $\$ 150,000$ a year or more (9). Level of education was also a categorical variable ranging from no education or grades 1 through 8 (1) to 
post-graduate training following a 4-year degree (7).

Conventional Attitudes. Two items were employed to assess for conventional attitudes. Acceptance of premarital sex was determined through the question "If a man and woman have sexual relations before marriage do you think it is," "Not wrong at all" (1) to "Always or almost always wrong" (3). Acceptability of divorce was determined by having the respondent choose which statement best fit his or her views about divorce: "Divorce is painful but preferable to maintaining an unhappy marriage" (1) to "Divorce should be avoided except in an extreme situation" (2). These items were entered separated for the analysis.

Parents' marital status. One item was used to determine the parents' marital status: "What was the marital status of your parents during the time you were growing up; were they married, divorced, separated, widowed, or never married to each other?" Responses were recoded as "Married" (1) and "Divorced or separated" (0). The categories of "widowed" and "never married" were excluded from the analysis, which represented about $8 \%$ of responses.

Relationship history variables. Two variables were examined related to the respondent's relationship history. Current marital status was assessed through one item: “Are you currently married, living with a partner, divorced, separated, or widowed?" The responses were recoded into "Currently married" (1) or "Currently divorced/separated" (0). To determine if the respondent had ever cohabited, one item asked "Have you ever lived together with a partner without being married?" Possible responses were "Yes" (1) or "No" (0).

Reasons for marriage. Reasons for marriage were determined from the open-ended question: "Why did you decide to get married rather than just live together?" Commitment theory was used as a conceptual framework for coding the responses as dedication (1), constraint (0), or other (see Table 2). The data had already been grouped into broad categories by the Pew 
Research Center (e.g., "wanting to spend the rest of our lives together" and "religious reasons." The three members of the research team worked collaboratively to classify each category as either a constraint reason or a dedication reason. The first and third author independently coded the "other" category as either "dedication," "constraint," or "other." An interrater reliability analysis was calculated to determine the consistency between the coders. The Kappa statistic indicated "substantial" agreement between the two coders $(\kappa=.79, \mathrm{p}<.001$; Landis \& Koch, 1977). This is an adequate level of agreement, given that the "other" category contained all of the most difficult responses to code. In cases where there was a discrepancy in coding, the second author was consulted to break the tie. The cases remaining in the "other" category were coded as missing because there was no way to interpret the responses in a meaningful way.

Life Satisfaction. One item assessed for life satisfaction: "Please tell me how satisfied you are with your life overall." Response choices ranged from "Very satisfied" (1) to "Very dissatisfied" (4). The responses were recoded as "Very satisfied" (1) to "Less than very satisfied" (0).

\section{Results}

In order to address our research questions, a series of binary logistic regression models were conducted. Men and women were analyzed separately due to the reported differences in commitment processes between the genders that have been documented in previous research studies (Givertz \& Segrin, 2005). In addition, a significant difference was found using the current data regarding men (68.2\% identified dedication and $31.8 \%$ constraint) and women's $(72.1 \%$ identified dedication and $27.9 \%$ constraint $)$ endorsement of commitment type $\left(\chi^{2}(1)=\right.$ $8.16, p<.01)$

Table 3 contains the binary logistic regression analysis predicting commitment type 
(dedication versus constraint) in the decision to marry rather than cohabit for the demographic, attitudinal, and relationship history variables. In order to control for basic demographic variables, age, education, and income were entered in step 1 of the model. The conventionality items and parents' marital status were entered in Step 2 of the model because they are known predictors of dedication and constraint, having been investigated in prior studies. Finally, the respondents' prior cohabitation history and current marital status were added to the model in step 3 . These two variables were added last because they represent new constructs that are yet to be examined in relation to commitment type. Each step significantly increased the predictive accuracy of the logistic regression model for both men and women, according to the step statistic in the omnibus tests of model coefficients (represented as a chi-square in the table).

In the final model, every variable significantly predicted men's commitment type. Higher levels of income were associated with an increase in the likelihood of marrying for dedication (odds ratio $=1.09, p<.001$ ), while higher levels of education and being older were linked with a decrease in the likelihood of marrying for dedication (odds ratio $=.89, p<.001$; odds ratio $=.98$, $\mathrm{p}<.01)$. The conventional belief that premarital sex is always or almost always wrong was associated with a $27 \%$ decrease in the likelihood of marrying for dedication (odds ratio $=.73, p<$ .001). Believing that divorce should be avoided except in an extreme situation was related to a $26 \%$ decrease in the odds of choosing marriage based on a dedication reason (odds ratio $=.74, p$ $<.001)$. The men that had experienced a parental divorce or separation were more likely to endorse a constraint reason for marriage (odds ratio $=.74, p<.05$ ). Finally, those men who had cohabited were $32 \%$ (odds ratio $=1.32, p<.05)$ more likely to choose marriage out of dedication and currently married men were 2.4 times more likely to marry for dedication than constraint reasons (odds ratio $=2.41, p<.001)$. 
Each variable was significantly predictive of commitment type for women except, age, income, and parent's marital status. Higher levels of education resulted in greater odds in marrying for dedication reasons (odds ratio $=1.14, p<.001$ ). The belief that premarital sex is always or almost always wrong indicated a $44 \%$ decrease in the odds of marrying for dedication (odds ratio $=.56, p<.001)$ and having a more conventional attitude toward divorce led to a $30 \%$ decrease in the likelihood of choosing marriage for dedication (odds ratio $=.70, p<.001$ ). Finally, women that had cohabited prior to marriage were 1.4 times more likely to have chosen marriage for dedication than constraint reasons (odds ratio $=1.40, p<.01$ ) and those that were currently married were over 1.8 times more likely to endorse dedication over constraint (odds ratio $=1.84, p<.001)$

Table 4 contains the binary logistic regression model assessing how commitment type in the decision to marry rather than cohabit predicts subsequent life satisfaction. Once again, the demographic variables of age, income, and education were entered into Step 1 of the model. Type of commitment (dedication or constraint) was then added in at Step 2, in order to assess its contribution beyond the demographic variables. Both steps significantly improved the predictive power of life satisfaction for men; however, the second step did not show a significant improvement in ability to predict life satisfaction for women.

For men, age and income were significant predictors of overall life satisfaction, with increased age decreasing the likelihood of being very satisfied with life by $7 \%$ (odds ratio $=.93$, $\mathrm{p}<.001$ ) and greater income increasing the odds of being very satisfied by $23 \%$ (odds ratio $=$ $1.23, \mathrm{p}<.001)$. For women, income and education both were significantly related to life satisfaction, with greater income resulting in being highly satisfied with life (odds ratio $=1.15, \mathrm{p}$ $<.001$ ) and higher levels of education resulting in being less than very satisfied with life (odds 
ratio $=.94, \mathrm{p}<.05)$

Taking into account commitment type, men choosing marriage over cohabitation for dedication reasons are nearly 1.7 times more likely to be very satisfied with life compared to men whose decision to marry was driven by constraint reasons (odds ratio $=1.66, p<.001$ ). For women, the type of commitment most salient in the decision to marry rather than cohabit was not related to life satisfaction (odds ratio $=1.02, \mathrm{p}<\mathrm{n} . \mathrm{s}$. ).

\section{Discussion}

This study sought to identify the demographic, attitudinal, and relationship history variables that predict whether men and women choose to marry (rather than cohabit) for personal dedication or constraint reasons and whether the commitment related reason for marrying is associated with life satisfaction when.

Perhaps the most significant result from this study is that marrying (rather than cohabiting) for personal dedication reasons is related to higher levels of overall life satisfaction for men, but not for women. This disparity could be attributed to the differing conceptualizations of cohabitation men and women hold. For women, cohabitation is much more likely to be perceived as one stage along the path to marriage (Thornton, Axinn, \& Xie, 2007). As a result, the decision-making process associated with deciding between marriage and cohabitation will ultimately be inconsequential if cohabitation is perceived to be one part of a marriage trajectory. This conceptualization of cohabitation does not seem to hold true for men. It is more likely for a man to view cohabitation as a distinct relationship state separate from marriage (Thornton et al., 2007). Therefore, the decision-making process associated with choosing marriage over cohabitation is likely to have a far more pronounced impact on men's personal well-being because choosing to cohabit is not conceived as a prelude to marriage. Prior research lends 
further support to this conclusion, in that men's cohabitation history significantly impacts level of dedication commitment, whereas prior cohabitation for women does not influence dedication commitment (Stanley et al., 2004).

The finding that the type of commitment driving the decision to marry rather than cohabit impacts later personal well-being for men but not women represents a contribution to the literature in two ways. First, this suggests that the relational forces shaping personal well-being for men and women are different. This study investigated the type of commitment operating during a decision made in the past (whether to marry or cohabit). It could be that personal wellbeing for women would be more impacted by viewing the type of commitment endorsed currently in their marital relationship. Another possibility is that commitment might play a more important role in maintaining the stability of relationships for women, but it is characteristics of the relationship itself that more directly impact personal well-being, such as conflict style or quality of communication. Second, this study suggests that examining the impact of decisionmaking during major relationship transitions on later personal well-being might not hold as much explanatory power for women as it does for men. It is possible that women's decision-making (and the commitment driving those decisions) might be a more fluid process that is not punctuated as dramatically by a major relationship transition, such as moving from cohabitation to marriage. Whereas men's decision-making could be prompted by the relationship transition itself. This is an area worthy of future investigation.

Turning to the analyses predicting personal dedication and constraint, current marital status turned out to hold the most predictive power. Specifically, those currently married are more likely to have married for dedication reasons than those currently divorced or separated for both men and women, but this finding was stronger for men (odds ratio $=2.41, \mathrm{p}<.001)$ than for 
women (odds ratio $=1.84, \mathrm{p}<.001$ ). Intuitively, one would expect those who choose to marry because of positive attributes in their partner would be more likely to remain married when compared to those who made that decision because of an outside force pushing them toward marriage (religious, societal, or family pressure). While constraints are an important component of commitment that contribute to relationship stability during times of relationship distress (Givertz \& Segrin, 2005; Stanley \& Markman, 1992), if they are the primary factor in one’s decision to marry, that may be an early indicator of relationship problems. In addition, married individuals still tend to report higher levels of dedication than cohabiters (Stanley et al., 2004).

Related to cohabitation history, both men and women who had cohabited prior to marriage were more likely to marry for dedication reasons than constraint reasons. At first glance, these results seem to contradict previous research that cohabiters often "slide" into marriage because of the many constraints associated with their living together rather than making a conscious decision to marry out of personal dedication (Rhoades et al., 2009b). The component missing from the current study that could shed more light on these results would be the timing of cohabitation (Stanley \& Markman, 2006). For example, those who have a commitment to marry before cohabiting would be less likely to "slide" into marriage based on current constraints in the relationship. Similarly, it is possible that those who have cohabited with more than one person are also more likely to end a relationship rather than allow constraints to pull him or her into a marriage. Finally, it could also be that cohabiters are less traditional and therefore less likely to endorse social or religious reasons (constraints) related to their decision to marry rather than to cohabit.

The results for the conventionality variables are quite interesting. The prior study that investigated conventional attitudes in relation to dedication and constraint found that higher 
levels of conventionality are associated with higher levels of dedication (Givertz et al., 2009).

The findings in the current study are just the opposite, with more conventional attitudes toward divorce and premarital sex being associated with a greater likelihood of endorsing constraint reasons for marrying rather than cohabiting for both men and women. This apparent contradiction could be attributed to the fact that the Givertz et al. study examined conventional attitudes only in conjunction with relationship process variables (conflict style and level of interdependence). Therefore, it is possible that the contribution of conventional attitudes was masked by the role of the relationship process variables in predicting commitment type. Furthermore, the sample employed by Givertz et al. was a convenience sample of college students, indicating their findings may not be generalizable to the broader population. In the current study, since the primary question of interest dealt with the decision to marry rather than cohabit, it could be that those individuals who hold more conventional attitudes in general would be more likely to endorse a constraint reason for choosing marriage because they hold a religious or moral belief against cohabiting. Therefore, the nature of the question, why they chose to marry their spouse rather than live together could have elicited responses from more traditional or conventional participants that made it clear that cohabiting was not an option as it went against their values.

Finally, the influence of parental divorce was consistent with prior research for men, in that those from divorced families were more likely to choose marriage over cohabitation out of constraint than dedication (Jacquet \& Surra, 2001). However, parent's marital status was not useful in predicting commitment type for women. It is possible that men who experienced a parental divorce would be apprehensive about entering marriage, which explains why it may take constraints to pull them into marriage compared to men whose parents did not divorce. However, 
it is not clear why parental divorce would play no role in the type of commitment driving women's decisions in this sample. Clearly, this is an area for future investigation. Finally, the purpose for including demographic variables in the current study was to control for their influence in the analyses since a national sample was being employed. Many of the demographic variables ended up significantly contributing to the regression models predicting both commitment type and life satisfaction. Notably, level of education operates in opposite directions for men and women in the analyses conducted in this study. This is a potentially fruitful area to be investigated in future research.

\section{Limitations and Implications for Future Research}

Several limitations in the current study can inform future research in this area. First, as with any secondary data set (Collins, Welsh, \& Furman, 2009), there were several variables not included that would have been useful in our present investigation. In the present study, including common and important relationship process variables would have been pertinent to gaining a more complete picture as to how marrying for dedication versus constraint reasons affects not only life satisfaction, but the relationship in general. This may have provided more insight as to how commitment type influences men and women's experiences and interactions in their current relationship. Also, there may be other demographic and socioeconomic variables that might provide useful information such as race, occupation, and geographic location. Second, although we only included participants age $18-49$, cohabitation is much more widespread and socially acceptable for the current cohort of young adults than it would have been for participants who are now in their 40s. Therefore, it is possible that older participants did not have a clear "choice" between marriage and cohabitation and therefore were more likely to be influenced by constraints in their decision to marry. Third, participants reported in the present their reasons for 
an event (their marriage) that happened sometime in the past. Therefore, memory bias due to time, the current state of their marriage, as well as some other life event could influence their current views about their original reasons for getting married. Finally, our data were from individuals, not couples, and it is likely that the mutual influence that couples have on each other's commitment type and level could shed further light on the relationship between the decision to marry, commitment processes, and personal well being. This presents an opportunity for future studies to look more closely as to how commitment type affects the couple dyad.

In conclusion, this exploratory study introduces the potential importance of commitment theory in understanding the decision to marry. Specifically, results show that several demographic, attitudinal, and relationship history variables predict endorsement of personal dedication and constraint commitment and that type of commitment is also associated with life satisfaction for men. Future studies that explore the relationship between commitment type and other relationship process variables, such as attachment and conflict, may also be worth studying, as these have shown to be important constructs needed to understand couple interaction (Feeney, 2008). 


\section{References}

Adams, J. M., \& Jones, W. H. (1997). The conceptualization of marital commitment: An integrative analysis. Journal of Personality and Social Psychology, 72, 1177-1196.

Arriaga, X. B., \& Agnew, C. R. (2001). Being committed: Affective, cognitive, and conative components of relationship commitment. Personality and Social Psychology Bulletin, 27, 1190-1203.

Bumpass, L., \& Lu, H. H. (2000). Trends in cohabitation and implications for children's family contexts in the United States. Population Studies, 54, 29-41.

Collins, W. A., Welsh, D. P., \& Furman, W. (2009). Adolescent romantic relationships. Annual Review of Psychology, 60, 631-652.

Feeney, J. A. (2008). Adult romantic attachment: Developments in the study of couple relationships. In J. Cassidy \& P. R. Shaver (Eds.), Handbook of attachment: Theory, research, and clinical applications (pp. 456-481). New York: Guilford.

Givertz, M., Segrin, C., \& Hanzal, A. (2009). The association between satisfaction and commitment differs across marital couple types. Communication Research, 36, 561-584.

Givertz, M. \& Segrin, C. (2005). Explaining personal and constraint commitment in close relationships: The role of satisfaction, conflict responses, and relational bond. Journal of Social and Personal Relationships, 22, 757-775.

Holbrook, A. L., Krosnick, J. A., \& Pfent, A. (2008). The causes and consequences of response rates in surveys by the new media and government contractor survey research firms. In J. M. Lepkowski et al. (Eds.), Advances in Telephone Survey Methodology (pp. 499-528). Hoboken, New Jersey: John Wiley \& Sons, Inc.

Jacquet, S. E., \& Surra, C. A. (2001). Parental divorce and premarital couples: Commitment and 
other relationship characteristics. Journal of Marriage and Family, 63, 627-638.

Johnson, M. P., Caughlin, J. P., \& Huston, T. L. (1999). The tripartite nature of marital commitment: Personal, moral, and structural reasons to stay married. Journal of Marriage and the Family, 61, 160-177.

Kline, G. H., Stanley, S. M., Markman, H. J., Olmos-Gallo, P. A., St. Peters, M., Whitton, S. W., \& Prado, L. M. (2004). Timing is everything: pre-engagement cohabitation and increased risk for poor marital outcomes. Journal of Family Psychology, 18, 311-318.

Landis, J. R., Koch, G. G. (1977). The measurement of observer agreement for categorical data. Biometrics, 33, 159-174.

Manning, W. D., Longmore, M. A., \& Giordano, P. C. (2007). The changing institution of marriage: Adolescents' expectations to cohabit and to marry. Journal of Marriage and Family, 69, 559-575.

Manning, W. D., \& Bulanda, R. E. (2006). Cohabitation and measurement of family trajectories. In S. Hofferth \& L. Casper (Eds.), Handbook of Measurement Issues in Family Research (199-219). Mahwah, NJ: Lawrence Erlbaum Associates.

Murstein, B. I., \& MacDonald, M. G. (1983). The relationship of “exchange-orientation” and “commitment" scales to marriage adjustment. International Journal of Psychology, 18, 297-311.

Pew Research Center Social and Demographic Trends. (2007). February-March 2007 Social Trends Survey [Date file and code book]. Retrieved from http://pewsocialtrends.org/downloads/

Rhoades, G. K., Stanley, S. M., \& Markman, H. J. (2009a). Couples' reasons for cohabitation: Associations with individual well-being and relationship quality. Journal of Family 
Issues, 30, 233-258.

Rhoades, G. K., Stanley, S. M., \& Markman, H. J. (2009b). The pre-engagement cohabitation effect: A replication and extension of previous findings. Journal of Family Psychology, 23, 107-111.

Sabatelli, R. M., \& Cecil-Pigo, E. F. (1985). Relational interdependence and commitment in marriage. Journal of Marriage and the Family, 47, 931-937.

Smock, P. J. (2000). Cohabitation in the United States: An appraisal of research themes, findings, and implications. Annual Review of Sociology, 26, 1-20.

Stanley, S. M., \& Markman, H. J. (1992). Assessing commitment in personal relationships. Journal of Marriage and the Family, 54(3), 595-608.

Stanley, S M., Rhoades, G. K., Markman, H. J. (2006). Sliding versus deciding: Inertia and the premarital cohabitation effect. Family Relations, 55, 499-509.

Stanley, S. M., Whitton, S. W., \& Markman, H. J. (2004). Maybe I do: Interpersonal commitment and premarital or nonmarital cohabitation. Journal of Family Issues, 25(4), 496-519.

Thornton, A., Axinn, W. G., \& Xie, Y. (2007). Marriage and Cohabitation. Chicago, IL: The University of Chicago Press.

Thornton, A., \& Young-DeMarco, L. (2001). Four decades of trends in attitudes toward family issues in the United States: The 1960s through the 1990s. Journal of Marriage and Family, 63, 1009-1037.

Whitton, S. W., Rhoades, G. K., Stanley, S. M., \& Markman, H. J. (2008). Effects of parental divorce on marital commitment and confidence. Journal of Family Psychology, 22, 789793. 
Wilcox, W. B., \& Marquardt, E. (2009). The state of our unions: Marriage in America 2009. Charlottesville, VA: National Marriage Project. 
Table 1

Correlations for Study Variables (Men Above the Diagonal and Women Below).

\begin{tabular}{|c|c|c|c|c|c|c|c|c|c|c|}
\hline Variables & 1 & 2 & 3 & 4 & 5 & 6 & 7 & 8 & 9 & 10 \\
\hline 1. Age & 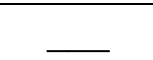 & $.28 * * *$ & $.05 * *$ & $.04 *$ & $-.09 * * *$ & $.11 * * *$ & .02 & $-.11 * * *$ & $.04 *$ & $-.09 * * *$ \\
\hline 2. Income & $.25 * * *$ & 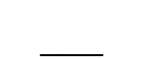 & $.56 * * *$ & -.01 & .02 & $.19 * * *$ & .01 & $.18 * * *$ & $-.29 * * *$ & $.04 *$ \\
\hline 3. Education & $.09 * * *$ & $.44 * * *$ & 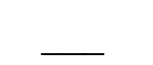 & $-.07 * * *$ & .03 & $.16^{* * *}$ & $-.06 * *$ & $.17 * * *$ & $-.22 * * *$ & -.04 \\
\hline 4. Premarital Sex & $.10 * * *$ & $-.07 * * *$ & $.04 *$ & 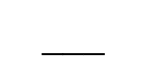 & $.27 * * *$ & $.10 * * *$ & $-.42 * * *$ & $.06 * *$ & $-.12 * * *$ & $-.16 * * *$ \\
\hline 5. Divorce & .01 & $.06 * * *$ & .01 & $.20 * * *$ & $\underline{-}$ & $.06^{* *}$ & $-.10 * * *$ & $.09 * * *$ & $-.11 * * *$ & $-.09 * * *$ \\
\hline 6. Parent's Marital & $.17 * * *$ & $.21 * * *$ & $.12 * * *$ & $.05 * *$ & $.09 * * *$ & - & $-.12 * * *$ & -.01 & -.03 & $-.08 * * *$ \\
\hline 7. Cohabit History & -.03 & $-.12 * * *$ & -.01 & $-.26 * * *$ & $-.05 *$ & $-.17 * * *$ & 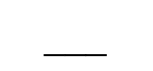 & $-.07 * *$ & $.22 * * *$ & $.10 * * *$ \\
\hline 9. Life Satisfaction & .04 & $-.16 * * *$ & $-.06 * *$ & -.03 & $-.06 * *$ & $-.07 * * *$ & .04 & $-.27 * * *$ & & -.04 \\
\hline 10. Commitment Type & $-.11 * * *$ & -.02 & -.01 & $-.22 * * *$ & $-.20 * * *$ & -.04 & $.05 * *$ & .02 & -.02 & \\
\hline
\end{tabular}

$*_{\mathrm{p}}<.05, * *_{\mathrm{p}}<.01, * * *_{\mathrm{p}}<.001$ 
Table 2

Definitions of Commitment Type and Respondent Exemplars that Represent Each Commitment Type as a Reason for Marrying Rather than Cohabiting

\begin{tabular}{|c|c|c|}
\hline Commitment Type & Definition & Exemplars \\
\hline \multirow[t]{4}{*}{ Dedication } & $\begin{array}{l}\text { Forces that motivate } \\
\text { connection; all of the } \\
\text { positive factors associated } \\
\text { with the relationship }\end{array}$ & $\begin{array}{l}\text { "Because we loved one } \\
\text { another and wanted to spend } \\
\text { the rest of our lives } \\
\text { together." }\end{array}$ \\
\hline & & $\begin{array}{l}\text { "We loved each other and } \\
\text { were very happy together." }\end{array}$ \\
\hline & & $\begin{array}{l}\text { "Because I wanted to spend } \\
\text { the rest of my life with my } \\
\text { husband as a partner. I } \\
\text { couldn't see the rest of my life } \\
\text { without him." }\end{array}$ \\
\hline & & $\begin{array}{l}\text { "We decided that we wanted } \\
\text { to be together and live and } \\
\text { grow and be a family for the } \\
\text { rest of our lives." }\end{array}$ \\
\hline \multirow[t]{4}{*}{ Constraint } & $\begin{array}{l}\text { Forces that increase the } \\
\text { cost of leaving; religious } \\
\text { and moral convictions }\end{array}$ & $\begin{array}{l}\text { "I don't think it's right to just } \\
\text { live with someone." }\end{array}$ \\
\hline & & $\begin{array}{l}\text { "Wanted son to grow up in } \\
\text { home." }\end{array}$ \\
\hline & & $\begin{array}{l}\text { "That would not fly with my } \\
\text { parents." }\end{array}$ \\
\hline & & $\begin{array}{l}\text { "Because I was pregnant and } \\
16 \text { years old." }\end{array}$ \\
\hline \multirow[t]{2}{*}{ Other } & $\begin{array}{l}\text { Researchers' inability to } \\
\text { determine responses in a } \\
\text { meaningful way }\end{array}$ & $\begin{array}{l}\text { "I was looking at the cover of } \\
\text { the book without reading it." }\end{array}$ \\
\hline & & $\begin{array}{l}\text { "Well, it had nothing to do } \\
\text { with children." }\end{array}$ \\
\hline
\end{tabular}


Table 3

Binary Logistic Regression Predicting Commitment Type

\begin{tabular}{|c|c|c|c|c|c|c|}
\hline \multirow[b]{2}{*}{ Predictor } & \multicolumn{3}{|c|}{$\operatorname{Men}(n=256)$} & \multicolumn{3}{|c|}{ Women $(\mathrm{n}=328)$} \\
\hline & $B$ & $S E$ & $\operatorname{Exp}(B)$ & $B$ & $S E$ & $\operatorname{Exp}(B)$ \\
\hline \multicolumn{7}{|l|}{ Step 1} \\
\hline Age & -0.03 & 0.01 & $0.97 * * *$ & -0.01 & 0.01 & $0.99 *$ \\
\hline Income & 0.09 & 0.03 & $1.10 * *$ & 0.04 & 0.03 & 1.04 \\
\hline Education & -0.10 & 0.03 & $0.90 * *$ & 0.14 & 0.04 & $1.15 * * *$ \\
\hline Constant & 0.25 & 0.33 & 1.28 & -1.46 & 0.29 & $0.23 * * *$ \\
\hline & \multicolumn{3}{|c|}{$\chi^{2}(3)=21.78, p<.001$} & \multicolumn{3}{|c|}{$\chi^{2}(3)=29.58, p<.001$} \\
\hline \multicolumn{7}{|c|}{ t } \\
\hline Age & -0.03 & 0.01 & $0.97 * * *$ & -0.01 & 0.01 & 0.99 \\
\hline Income & 0.10 & 0.03 & $1.10 * *$ & 0.04 & 0.03 & 1.04 \\
\hline Education & -0.11 & 0.04 & $0.89 * *$ & 0.14 & 0.04 & $1.15 * * *$ \\
\hline Premarital Sex & -0.37 & 0.06 & $0.69 * * *$ & -0.62 & 0.07 & $0.54 * * *$ \\
\hline Divorce & -0.15 & 0.05 & $0.86 * *$ & -0.33 & 0.06 & $0.72 * * *$ \\
\hline Parent's Marital & -0.38 & 0.14 & $0.69 * *$ & -0.04 & 0.14 & 0.96 \\
\hline Constant & 1.57 & 0.40 & $4.81 * * *$ & 0.38 & 0.34 & 1.46 \\
\hline & \multicolumn{3}{|c|}{$\chi^{2}(3)=72.31, p<.001$} & \multicolumn{3}{|c|}{$\chi^{2}(3)=147.44, p<.001$} \\
\hline \multicolumn{7}{|l|}{ Step 3} \\
\hline Age & -0.02 & 0.01 & $0.98 * *$ & -0.01 & 0.01 & 0.99 \\
\hline Income & 0.09 & 0.03 & $1.09 * *$ & 0.01 & 0.03 & 1.01 \\
\hline Education & -0.11 & 0.04 & $0.89 * * *$ & 0.13 & 0.04 & $1.14 * * *$ \\
\hline Premarital Sex & -0.32 & 0.07 & $0.73 * * *$ & -0.58 & 0.07 & $0.56 * * *$ \\
\hline Divorce & -0.17 & 0.05 & $0.84 * * *$ & -0.36 & 0.06 & $0.70 * * *$ \\
\hline Parent's Marital & -0.30 & 0.14 & $0.74 *$ & 0.02 & 0.15 & 1.02 \\
\hline Cohabit History & 0.27 & 0.11 & $1.32 *$ & 0.33 & 0.12 & $1.40 * *$ \\
\hline Marital Status & 0.88 & 0.18 & $2.41 * * *$ & 0.61 & 0.18 & $1.84 * * *$ \\
\hline Constant & 0.32 & 0.44 & 1.38 & -0.30 & 0.38 & 0.74 \\
\hline & \multicolumn{3}{|c|}{$\chi^{2}(2)=30.94, p<.001$} & \multicolumn{3}{|c|}{$\chi^{2}(2)=17.22, p<.01$} \\
\hline
\end{tabular}

Note: Commitment Type Coding: Constraint $=0$ and Dedication $=1$

$* \mathrm{p}<.05, * * \mathrm{p}<.01, * * * \mathrm{p}<.001$ 
Table 4

Binary Logistic Regression Predicting Life Satisfaction

\begin{tabular}{|c|c|c|c|c|c|c|}
\hline \multirow[b]{2}{*}{ Predictor } & \multicolumn{3}{|c|}{ Men $(n=283)$} & \multicolumn{3}{|c|}{ Women $(\mathrm{n}=384)$} \\
\hline & $B$ & $S E$ & $\overline{E x p}(B)$ & $B$ & $S E$ & $\overline{\operatorname{Exp}}(B)$ \\
\hline \multicolumn{7}{|l|}{ Step 1} \\
\hline Age & -0.07 & 0.01 & $0.93 * * *$ & -0.01 & 0.01 & 0.99 \\
\hline Income & 0.20 & 0.03 & $1.23 * * *$ & 0.14 & 0.02 & $1.15 * * *$ \\
\hline Education & 0.05 & 0.03 & 1.05 & -0.06 & 0.03 & $0.94 *$ \\
\hline Constant & 1.79 & 0.31 & $5.98 * * *$ & -0.40 & 0.23 & 0.67 \\
\hline & \multicolumn{3}{|c|}{$\chi^{2}(3)=186.39, p<.001$} & \multicolumn{3}{|c|}{$\chi^{2}(3)=34.22, p<.001$} \\
\hline \multicolumn{7}{|l|}{ Step 2} \\
\hline Age & -0.07 & 0.01 & $0.93 * * *$ & -0.01 & 0.01 & 0.99 \\
\hline Income & 0.20 & 0.03 & $1.22 * * *$ & 0.14 & 0.02 & $1.15 * * *$ \\
\hline Education & 0.07 & 0.32 & $1.07 *$ & -0.06 & 0.03 & $0.94 *$ \\
\hline Commitment Type & e 0.50 & 0.10 & $1.66 * * *$ & 0.02 & 0.09 & 1.02 \\
\hline Constant & 1.50 & 0.31 & $4.49 * * *$ & -0.41 & 0.24 & 0.67 \\
\hline \multicolumn{4}{|c|}{$\chi^{2}(1)=24.25, p<.001$} & \multicolumn{3}{|c|}{$\chi^{2}(1)=0.02, p<$ n.s. } \\
\hline
\end{tabular}

Note: Life Satisfaction Coding: Less than very satisfied $=0$ and Very satisfied $=1$ $*_{\mathrm{p}}<.05, * * \mathrm{p}<.01, * * * \mathrm{p}<.001$ 